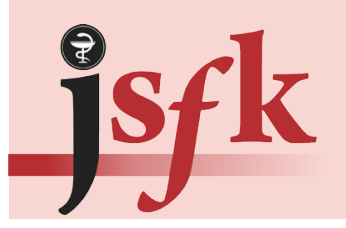

Jurnal Sains Farmasi \& Klinis (p- ISSN: 2407-7062 | e-ISSN: 2442-5435)

diterbitkan oleh Ikatan Apoteker Indonesia - Sumatera Barat homepage: http://jsfkonline.org

\title{
Kajian Kimia Fraksi Etil Asetat dari Kulit Batang Kayu Pahit (Picrasma Javanica Bl.)
}

(Chemical study of ethyl acetate fraction of bark of Picrasma Javanica Bl.)

\author{
Sri Hainil ${ }^{1 *}$, Dayar Arbain² \& Deddi Prima Putra ${ }^{2}$ \\ ${ }^{2}$ Sekolah Tinggi Ilmu Kesehatan Mitra Bunda Persada Batam \\ ${ }^{2}$ Fakultas Farmasi Universitas Andalas
}

\author{
Keywords: \\ structure \\ elucidation, \\ Picrasma javanica
}

$B l$.

Kata kunci: elusidasi struktur, Picrasma javanica

$\mathrm{Bl}$.
ABSTRACT: N-1 main compound from ethyl acetate fraction of kayu pahit bark (Picrasma Javanica Bl) has been isolated and characterized with column chromatography and continued with preparative chromatography. Based on structure elucidation and analysis of spectra from ultraviolet (UV) spectroscopy, infra red (IR) spectroscopy, ${ }^{1} \mathrm{H}$ MRI (Magnetic Resonance Imaging) spectroscopy, ${ }^{13} \mathrm{C}$ MRI spectroscopy, mass spectroscopy, COSY (Correlated Spectroscopy), HSQC (Heteronuclear Single Quantum Correlation), HMBC (Heteronuclear Multiple Bond Correlation) and literature study showed that the isolated compound was javanicin $A$.

ABSTRAK: Senyawa utama N-1 dari fraksi etil asetat kulit batang kayu pahit (Picrasma Javanica $\mathrm{Bl}$ ) telah diisolasi dan dikarakterisasi dengan kromatografi kolom dan dilanjutkan dengan kromatografi preparatif. Berdasarkan elusidasi struktur dan analisis data spektrum yang digunakan yang meliputi spektroskopi ultraviolet (UV), infra merah (IR), ' $\mathrm{H}$ RMI (Resonansi Magnet Inti), ${ }^{13} \mathrm{C}$ RMI, Massa, COSY (Correlated Spectroscopy), HSQC (Heteronuclear Single Quantum Correlation), HMBC (Heteronuclear Multiple Bond Correlation) dan studi literatur menunjukkan bahwa senyawa yang isolasi adalah Javanicin A.

\section{PENDAHULUAN}

Masyarakat Indonesia umumnya memiliki beragam latar belakang budaya etnik. Mereka menggunakan obat tradisional dengan memanfaatkan kekayaan alam di sekitarnya. Sumatera sebagai pulau keempat terbesar di dunia sangat kaya akan berbagai jenis biota tumbuhan tropis. Pada umumnya tumbuhan ini telah dimanfaatkan oleh nenek moyang orang Sumatera untuk berbagai keperluan seperti untuk upacara adat dan budaya, ekonomi, obat-obatan, racun dan lain-lain [1,2].

Penggunaan obat tradisional tersebut sangat berperan dalam usaha pencegahan penyakit dan peningkatan taraf kesehatan masyarakat. Penggunaannya sehari-hari berdasarkan pada pengalaman atau pengetahuan yang diteruskan

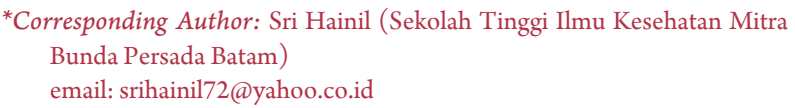


secara turun temurun namun belum banyak diteliti secara ilmiah tentang kandungan kimia dan khasiat farmakologinya $[1,3]$.

Tumbuhan Picrasma javanica Blume dikenal dengan nama Ki Brahma, Ki pahit, Kayu pahit, dan di Sunda dikenal sebagai tuba ulet. Di Sumatera Barat di daerah Baso Bukittinggi, dikenal sebagai "kayu paik". Tumbuhan ini telah digunakan masyarakat Baso secara tradisional sebagai obat penyakit kulit, malaria dan obat kuat [2,3].

Dalam rangka melanjutkan penelitian ini, khususnya tumbuhan lokal yang ada di Bukittinggi tersebut maka dilakukan isolasi kandungan kimia. Isolasi kandungan kimia dari "kayu paik" (Picrasma javanica.Bl) dilakukan dengan ekstraksi secara maserasi, yaitu suatu teknik penyarian dengan cara perendaman sampel tumbuhan dalam pelarut tertentu, sehingga senyawa yang dikandung dalam tumbuhan dapat ditarik oleh pelarut tersebut [4].

Kemudian dilanjutkan dengan pemeriksaan fraksi-fraksi dengan kromatografi lapis tipis, pemisahan salah satu komponen dengan metoda kromatografi kolom, kromatografi radial dan kromatografi preparatif. Terhadap hasil kolom yang didapat dilakukan pemurnian dengan cara rekristalisasi. Selanjutnya karakterisasi senyawa terpisah dilakukan dengan penentuan titik leleh, pemeriksaan dengan spektroskopi ultraviolet (UV), infrared (IR), massa, resonansi magnet inti (RMI) ${ }^{1} \mathrm{H}$ dan ${ }^{13} \mathrm{C}$, COSY (Correlated Spectroscopy), HSQC (Heteronuclear Single Quantum Correlation) dan HMBC (Heteronuclear Multiple Bond Correlation) $[5,6]$.

\section{METODE PENELITIAN}

Alat dan Bahan

Peralatan yang dipakai terdiri dari perlengkapan alat destilasi dan rotari evaporator $\left(\mathrm{BUCHI}^{\circledR}\right)$, chromatotron model 7024 USA, botol coklat 2,5 L, corong, timbangan analitik, oven listrik, kolom kromatografi dengan berbagai ukuran, kertas saring, corong pisah, chamber, lampu UV 254 model UV-Betrachter ${ }^{\circledR}$, Fisher Johns Melting Point apparatus, autoklaf Jall American model $25 \mathrm{X}$, kertas koran, Erlenmeyer, tabung reaksi, hot plate, magnetik stirer, spektronik-21, spektrofotometer UV-1601 Shimadzu, spektrometer IR Perkin Elmer, kapas, aluminium foil, stamfer dan montir

Bahan-bahan yang dipakai terdiri dari metanol, $n$-heksan, etil asetat, butanol, logam Mg, $\mathrm{HCl}$, pereaksi Dragendorff, pereaksi Mayer, asetat anhidrida, asam sulfat pekat, besi(III) klorida, plat KLT Kieselgel 60 F $254\left(\right.$ Merck $\left.^{\circledR}\right)$, silika gel 60 (Merck) (230-400 mesh), silika gel PF 254,

\section{Cara Kerja}

\section{Pengambilan sampel}

Sampel yang digunakan adalah kulit batang segar dari tumbuhan Picrasma javanica Bl. Tumbuhan ini diambil di Baso, Bukittinggi, Kabupaten Agam. Kulit batang dibersihkan dari kotoran, dipotong kecil-kecil kemudian ditimbang dan didapatkan berat sampel sebanyak $3,5 \mathrm{~kg}$.

\section{Identifikasi tumbuhan}

Contoh spesimen herbarium dengan nomor koleksi DA 230 disimpan di Herbarium Universitas Andalas, Padang dan Herbarium Bogorinae.

\section{Ekstraksi dan fraksinasi}

Sampel seberat 3,5 $\mathrm{kg}$ diekstraksi dengan metoda maserasi dengan cara perendaman sampel dalam metanol hingga menutupi semua permukaan sampel. Perendaman dilakukan dalam tujuh buah botol coklat 2,5 L dan disimpan ditempat terlindung cahaya matahari langsung, selama 5 hari, sambil sesekali diaduk. Maserat dipisahkan dari ampasnya dengan disaring dan ampasnya 
dimaserasi lagi. Proses maserasi diulang lagi sebanyak dua kali. Maserat dari tiga kali proses digabung kemudian diuapkan pelarutnya secara in vacuo sampai volume lebih kurang 1,6 L, sehingga didapatkan ekstrak kental metanol.

Ekstrak kental metanol tersebut ditambahkan asam asetat pekat $100 \mathrm{ml}$ dan cukupkan dengan aquadest sampai 2 L, sehingga didapatkan konsentrasi akhir asam asetat $5 \%$, lalu biarkan semalam. Maserat di dekantasi untuk memisahkan endapan dan larutan (fraksi asam/air). Bagian endapan ditambah lagi asam asetat dan aquadest, biarkan semalam, kemudian didekantasi lagi, sehingga diperoleh dua bagian yaitu bagian endapan (1) dan fraksi asam/air (2).

Bagian endapan (1) dikocok dengan metanol : air dengan perbandingan 2 : 1 , kemudian difraksinasi dalam corong pisah dengan n-heksan sebanyak 3 x $500 \mathrm{ml}$. Hasil fraksinasi diperoleh dua fraksi yaitu fraksi n-heksan dan fraksi metanol/ air. Fraksi n-heksan diuapkan dengan rotary evaporator dan didapatkan fraksi kental n-heksan seberat 4,02 $\mathrm{g}$.

Fraksi metanol/air selanjutnya difraksinasi dengan etil asetat, sehingga diperoleh dua fraksi yaitu fraksi etil asetat dan fraksi air. Fraksi etil asetat dicuci dengan aquadest dan didapatkan fraksi etil asetat dan fraksi air. Fraksi air yang didapatkan digabung. Fraksi etil asetat diuapkan dengan rotary evaporator dan didapatkan fraksi kental etil asetat seberat $2,11 \mathrm{~g}$.

Gabungan fraksi air selanjutnya difraksinasi dengan butanol sehingga diperoleh dua fraksi, yaitu fraksi butanol dan fraksi sisa. Fraksi butanol diuapkan in vacuo dan didapatkan fraksi kental butanol seberat $3 \mathrm{~g}$.

Bagian larutan (2) difraksinasi dengan n-heksan sebanyak 5 x $500 \mathrm{ml}$, sehingga diperoleh fraksi n-heksan dan fraksi sisa. Fraksi n-heksan diuapkan dengan rotari evaporator dan diperoleh fraksi n-heksan kental seberat 4 g. Fraksi sisa difraksinasi lagi dengan etil asetat sebanyak 6 x 500 $\mathrm{ml}$, sehingga diperoleh fraksi etil asetat asam dan fraksi sisa. Fraksi etil asetat asam diuapkan dengan rotari evaporator dan diperoleh fraksi etil asetat asam kental seberat 35 g. Fraksi sisa ditambah $\mathrm{NH}_{4} \mathrm{OH}$ sampai $\mathrm{pH}$ 8-9, kemudian difraksinasi lagi dengan etil asetat 4 x $500 \mathrm{ml}$ sehingga didapatkan fraksi etil asetat basa dan fraksi sisa. Fraksi etil asetat basa diuapkan dengan rotary evaporator dan diperoleh fraksi kental etil asetat basa seberat $15 \mathrm{~g}$. Fraksi sisa dinetralkan dengan penambahan asam asetat sampai $\mathrm{pH}$ 7, kemudian terakhir difraksinasi lagi dengan butanol sebanyak 4 x 500 $\mathrm{ml}$ dan didapatkan fraksi butanol dan fraksi sisa. Fraksi butanol diuapkan dengan rotary evaporator dan diperoleh fraksi kental butanol seberat $16 \mathrm{~g}$. Masing-masing ekstrak kental metanol, fraksi kental n-heksan, fraksi kental etil asetat dan fraksi kental butanol digabung sesamanya.

\section{Pemisahan dan pemurnian fraksi etil asetat}

Isolasi senyawa kimia utama dari fraksi etil asetat dilakukan dengan kromatografi kolom menggunakan fase diam silika gel 60 ukuran 230400 mesh dan fase gerak n-heksan, etil asetat dan metanol. Sebanyak 30 gram fraksi etil asetat dipreabsorpsi dengan cara melarutkannya dengan sedikit metanol, ditambahkan 30 gram silika kemudian diuapkan dengan rotary evaporator sampai membentuk serbuk.

Kolom dikemas dengan mensuspensikan silika gel 450 gram dalam pelarut n-heksan, kemudian dimasukkan kedalam kolom kromatografi yang ujungnya telah diberi kapas sambil diketok agar silikanya memadat. Sampel hasil preabsorpsi ini ditaburkan secara merata diatas suspensi silika didalam kolom kromatografi dan dielusi dengan fase gerak yang kepolarannya ditingkatkan secara bertahap.

Hasil kromatografi kolom ditampung dengan vial dan dimonitor dengan KLT, sebagai penampak 
noda digunakan lampu UV pada panjang gelombang $254 \mathrm{~nm}$. Vial yang memiliki noda sama digabung sehingga diperoleh fraksi 1 (vial 1-3) atau E1, fraksi 2 ( vial 4-28) atau E2, fraksi 3 (vial 2933 ) atau E3, fraksi 4 ( vial 34-46) atau E4, fraksi 5 (vial 49-52) atau E5, fraksi 6 (vial 50-76) atau E6. Dari monitor KLT yang dilakukan terhadap fraksi gabungan terlihat bahwa fraksi E1, E2, E3 atau (Et-1) mempunyai noda yang besar dengan intensitas yang tajam.

Fraksi Et-1 (15,87 g) dipisahkan lebih lanjut dengan kromatografi kolom menggunakan fase diam silika gel (300 gram) yang disuspensikan dalam pelarut n-heksana. Suspensi ini kemudian dimasukkan ke dalam kolom kromatografi yang ujungnya telah diberi kapas sambil diketok sampai silikanya memadat. Fraksi Et-1 dilarutkan dalam sedikit metanol, ditambahkan silika sama banyak, kemudian pelarutnya diuapkan dengan rotary evaporator sampai membentuk serbuk. Serbuk hasil preabsorpsi ini selanjutnya ditabur secara merata diatas suspensi silika gel dalam kolom kromatografi dan dielusi dengan fase gerak n-heksana, etil asetat dan metanol yang kepolarannya ditngkatkan secara bertahap (SGP) sesuai dengan perbandingan.

Fraksi yang keluar ditampung dengan vial dan dimonitor dengan KLT. Vial dengan Rf sama digabung sehingga diperoleh 5 fraksi yaitu fraksi A (vial 1-7), fraksi B ( vial 8-12), fraksi C (vial 1320), fraksi D (vial 21-33) dan fraksi E (vial 34-56).

Pada fraksi D terbentuk kristal pada dasar vial. Kristal ini kemudian dipisahkan dari larutannya dengan memipet larutan dari fraksi D dan dipindahkan ke vial lain. Hasil monitor dengan KLT terhadap kristal D menunjukkan 3 noda dibawah lampu UV dengan eluent diklorometan : metanol (19:1), sedangkan dengan etil asetat $100 \%$ telah menunjukkan satu noda. Kristal ini kemudian direkristalisasi dengan n-heksan - etil asetat dan dicek dengan KLT ternyata masih mempunyai tiga noda. Untuk selanjutnya dipisahkan lagi dengan cara kromatografi preparatif dengan fase diam silika gel PF 254 dan fase gerak diklorometan : metanol (19:1). Setelah dipisahkan dengan kromatografi preparatif pita yang didapat dilihat di bawah lampu UV, dikerok dan diekstraksi kemudian disaring. Berdasarkan hasil monitor KLT ternyata senyawa dapat memisah dengan jelas, baik dengan pelarut diklorometan : metanol (19:1) maupun dengan etil asetat $100 \%$. Selanjutnya kristal ini diberi nama senyawa $\mathrm{N}-1$ seberat $85 \mathrm{mg}$.

\section{HASIL DAN DISKUSI}

Pemeriksaan pendahuluan kandungan metabolit sekunder kulit batang Picrasma javanica. Bl menunjukkan bahwa tumbuhan ini mengandung alkaloid dan terpenoid

Dari 3,5 kg sampel segar kulit batang Picrasma javanica. Bl didapatkan ekstrak total metanol sebanyak 118,9 g, fraksi hexan 8,02 g (6,75 \%), fraksi etil asetat $37,11 \mathrm{~g}(31,21 \%)$ dan fraksi butanol $19 \mathrm{~g}(15,98 \%)$.

Dari hasil pemisahan dan pemurnian fraksi etil asetat (30 g) dengan kromatografi kolom dan kromatografi preparatif didapatkan senyawa $\mathrm{N}-1$ sebanyak $85 \mathrm{mg}$, berupa kristal jarum berwarna putih dengan jarak leleh 179-180o C

Data spektroskopi UV senyawa $\mathrm{N}-1$ dalam pelarut metanol memperlihatkan serapan maksimum pada panjang gelombang $271 \mathrm{~nm}$, absorban 0,7985

Data spektroskopi IR senyawa $\mathrm{N}-1$ memperlihatkan serapan kuat pada bilangan gelombang $3540 \mathrm{~cm}^{-1}, 1730 \mathrm{~cm}^{-1}, 1680 \mathrm{~cm}^{-1}, 1240$ $\mathrm{cm}^{-1}$.

Data spektroskopi ${ }^{1} \mathrm{H}$ RMI dalam $\mathrm{CDCl}^{3}$ menunjukkan adanya 5 buah sinyal singlet pada 1,24 ppm; 1,43 ppm; 1,04 ppm; 3,62 ppm dan 3,67 ppm, 2 buah sinyal doublet pada 4,07 ppm dan 1,04 ppm, 4 buah sinyal doublet of doublet pada pergeseran kimia 2,48 ppm, 2,66 ppm, 2,90 dan 4,14 serta 1 buah sinyal triplet pada 5,66 ppm. 
Data spektroskopi ${ }^{13} \mathrm{C}$ RMI dalam $\mathrm{CDCl}^{3}$, menunjukkan bahwa atom karbon primer sebanyak 5 buah pada pergeseran kimia 11,48 ppm, 14,71 ppm, 21,83 ppm, 55,58 ppm dan 62,08 ppm. Atom karbon skunder sebanyak 3 buah, yaitu pada pergeseran kimia 28,18 ppm, 28,47 ppm dan 29,51 ppm. Jumlah atom karbon tersier yaitu 8 buah pada pergeseran kimia 39,94 ppm, 36,26 ppm, 37,81 ppm, 44,89 ppm, 73,90 ppm, 82,76 ppm, 88,74 ppm dan 112,06 ppm. Sedangkan jumlah atom karbon quarterner sebanyak 5 buah pada pergeseran kimia 36,75 ppm, 47,86 ppm, 149,64 ppm, 170,46 ppm dan 204,71 ppm.

Korelasi proton-proton dan proton-karbon terlihat pada spektrum ${ }^{1} \mathrm{H}-{ }^{1} \mathrm{H}$ COSY,${ }^{1} \mathrm{H}-{ }^{19} \mathrm{C}$ HSQC dan ${ }^{1} \mathrm{H}-{ }^{19} \mathrm{C}$ HMBC.

Hasil pemeriksaan spektrum massa senyawa N-1 menggunakan metoda Electron Impact (EI) menunjukkan berat molekul 378 dengan rumus molekul $\mathrm{C}_{21} \mathrm{H}_{30} \mathrm{O}_{6}$.

Proses isolasi senyawa N-1 dari fraksi etil asetat kulit batang picrasma javanica.Bl adalah proses perajangan (dipotong-potong). Perajangan bertujuan untuk memperluas permukaan sampel segar agar kontak antara pelarut dengan sampel semakin luas. Hal ini menyebabkan penetrasi pelarut ke dalam membran sel akan lebih mudah sehingga mempercepat proses penarikan senyawasenyawa yang terkandung didalam sampel tersebut. Metoda ekstraksi yang digunakan adalah maserasi (perendaman), karena proses pengerjaan yang sederhana, hanya dengan merendam sampel dengan pelarut organik, dalam hal ini digunakan metanol selama beberapa hari sambil sesekali dikocok. Pemilihan metanol sebagai pelarut maserasi didasarkan pada kemampuan metanol untuk melarutkan hampir semua senyawa organik dalam tumbuhan, baik yang bersifat polar maupun non polar, mempunyai titik didih yang rendah (65oC) sehingga mudah diuapkan dan harganya relatif murah.Ekstrak metanol yang diperoleh, diuapkan pelarutnya secara in vacuo karena dalam keadaan vakum tekanan uap pelarut akan turun dan pelarut akan mendidih pada temperatur yang lebih rendah dari titik didihnya. Hal ini akan mengurangi kemungkinan kerusakan senyawa termolabil yang ada dalam sampel [7].

Fraksinasi dilakukan dengan menggunakan pelarut berdasarkan tingkat kepolarannya. Pelarut $n$-heksan akan menarik senyawa-senyawa non polar seperti klorofil, lemak, lilin dan senyawa non polar lainnya. Komponen yang tidak larut dengan n-heksan selanjutnya difraksinasi dengan etil asetat yang dapat menarik senyawa-senyawa semipolar, sedangkan senyawa-senyawa polar akan berada dalam fraksi air. Kemudian fraksi air ini, difraksinasi dengan butanol sehingga didapat fraksi butanol yang mengandung senyawa polar dan fraksi air sebagai fraksi sisa. Fraksi-fraksi yang didapat dipekatkan dengan rotary evaporator sehingga didapat ekstrak kental untuk tiap fraksi [8].

Pemisahan senyawa yang dituju didasarkan pada hasil skrining bioaktifitas khususnya terhadap kuassinoid. Karena itu pengerjaan selanjutnya dikhususkan pada fraksi tersebut.

Fraksi etil asetat dipisahkan dengan kromatografi kolom menggunakan silika gel 60 (230-400 mesh) sebagai fase diam. Fase gerak yang digunakan adalah pelarut n-heksan, etil asetat, metanol yang kepolarannya ditingkatkan secara bertahap. Selain kromatografi kolom digunakan juga kromatografi lapis tipis preparatif. Kromatografi ini digunakan terutama untuk memisahkan campuran senyawa dalam jumlah sedikit yang sukar dipisahkan dengan kromatografi kolom [6].

Pemisahan fraksi etil asetat dengan komatografi kolom menghasilkan 6 fraksi utama. Berdasarkan pola noda pada KLT terlihat bahwa fraksi 1 sampai dengan 3 memiliki tiga noda yang besar dan tajam namun pemisahannya belum sempurna dan masih 
ada senyawa minor lainnya. Karena itu fraksi 1 sampai dengan 3 dipisahkan lebih lanjut dengan kromatografi kolom yang dilanjutkan dengan kromatografi lapis tipis preparatif. Tiap langkah pemisahan senyawa dari fraksi selalu dimonitor dengan KLT sampai diperoleh satu noda.

Senyawa hasil isolasi secara kromatografi jarang yang langsung murni, ini dapat dilihat dari profil KLT nya yang masih terkontaminan. Salah satu teknik dalam proses pemurnian ini adalah secara rekristalisasi, yang didasarkan pada perbedaan kelarutan antara zat yang dimurnikan dengan pengotor dalam suatu pelarut tunggal atau campuran pelarut yang cocok. Proses rekristalisasi ini diulang beberapa kali hingga didapatkan kristal murni. Pemeriksaan kemurnian dinyatakan dengan pengukuran jarak leleh dan pola KLT dengan berbagai tipe pelarut [9].

Senyaw N-1 yang telah murni berupa kristal jarum berwarna putih, sebanyak $85 \mathrm{mg}$, dengan jarak leleh $179-180^{\circ} \mathrm{C}$. Pemeriksaan kromatografi senyawa $\mathrm{N}-1$ pada plat KLT menggunakan fase gerak etil asetat $100 \%$ dan diklorometana-metanol (19:1) memberikan nilai $\mathrm{Rf}$ berturut-turut 0,46 dan 0,60. Pemeriksaan kimia senyawa N-1 dengan vanilin-asam sulfat $1 \%$ memberikan warna merah muda. Ini menunjukkan bahwa senyawa $\mathrm{N}-1$ termasuk golongan triterpenoid.

Pemeriksaan spektrum UV senyawa $\mathrm{N}-1$ dalam metanol memberikan serapan maksimum pada panjang gelombang $271 \mathrm{~nm}$. Serapan ini menunjukkan adanya konjugasi $\mathrm{C}=\mathrm{C}-\mathrm{C}=\mathrm{O}$ pada cincin pertama dengan gugus karbonil pada atom C-1 memberikan panjang gelombang maksimum pada $271 \mathrm{~nm}$.

Dari pemeriksan spektum IR senyawa N-1 menunjukkan serapan kuat pada bilangan gelombang $3540 \mathrm{~cm}^{-1}$ yang diduga diberikan oleh gugus $\mathrm{OH}$. Serapan pada bilangan gelombang 3000 cm-1 diduga disebabkan karena adanya regangan C-H alifatik. Absorpsi pada $1730 \mathrm{~cm}-1$ merupakan absorpsi karakteristik dari gugus $\mathrm{C}=\mathrm{O}$ lakton. Regangan pada 1680 cm-1 dapat diterjemahkan sebagai regangan dari dari $\mathrm{C}=\mathrm{O}$ karbonil keton. Sinyal $1240 \mathrm{~cm}-1$ dapat berasal dari regangan C-O-.

Pemeriksaan spektrum ${ }^{1} \mathrm{H}$ senyawa $\mathrm{N}-1$ dalam $\mathrm{CDCl}^{3}$ memperlihatkan sinyal berupa singlet dengan integrasi 3 proton pada pergeseran kimia 3,62 ppm dan 3,67 ppm. Sinyal ini diduga sebagai sinyal proton dari gugus metil yang mengalami pergeseran kearah down field karena berikatan dengan atom oksigen dari metoksi. Dimana sinyal pada 3,62 ppm berasal dari gugus metoksi yang terikat pada $\mathrm{C}-2$, sedangkan satu gugus metoksi lagi terikat pada atom $\mathrm{C}-12$, sedangkan gugus $\mathrm{OH}$ terikat pada atom C-11. Sinyal doublet dengan integrasi 3 proton pada ${ }^{1} \mathrm{H}$ 1,04 ppm memiliki konstanta kopling (J) $7 \mathrm{~Hz}$. Menurut data COSY menunjukkan bahwa proton pada ${ }^{1} \mathrm{H} 1,04$ ppm berkorelasi langsung dengan proton pada ${ }^{1} \mathrm{H} 2,10$ ppm. Sinyal pada ${ }^{1} \mathrm{H} 1,04 \mathrm{ppm}(\mathrm{d}, 3 \mathrm{H}),{ }^{1} \mathrm{H}$ 1,24 ppm $(\mathrm{s}, 3 \mathrm{H})$ dan ${ }^{1} \mathrm{H} 1,43(\mathrm{~s}, 3 \mathrm{H})$ berasal dari 3 buah gugus metil. Dua buah sinyal dari metil yang berbentuk singlet ini berasal dari metil yang terdapat pada atom $\mathrm{C}-8$ dan atom $\mathrm{C}-10$ dan $\mathrm{C}-13$.

Data spektroskopi ${ }^{13} \mathrm{C} \mathrm{RMI}\left(\mathrm{CDCl}^{3}, 125 \mathrm{MHz}\right)$ menunjukkan bahwa atom karbon senyawa $\mathrm{N}-1$ ada 21 buah, yang terdiri dari atom karbon primer sebanyak 5 buah pada pergeseran kimia 11,48 ppm, 14,71 ppm, 21,83 ppm, 55,58 ppm dan 62,08 ppm. Atom karbon sekunder sebanyak 3 buah, yaitu pada pergeseran kimia $28,18 \mathrm{ppm}, 28,47 \mathrm{ppm}$ dan 29,51 ppm. Jumlah atom karbon tersier yaitu 8 buah pada pergeseran kimia 39,94 ppm, 36,26 ppm, 37,81 ppm, 44,89 ppm, 73,90 ppm, 82,76 ppm, 88,74 ppm dan 112,06 ppm. Sedangkan jumlah atom karbon quarterner sebanyak 5 buah pada pergeseran kimia 36,75 ppm, 47,86 ppm, 149,64 ppm, 170,46 ppm dan 204,71 ppm. Spektrum HSQC memperlihatkan hubungan proton dengan karbon tempatnya terikat, sedangkan spektrum 
HMBC dapat diketahui hubungan proton dengan karbon tetangganya yang berjarak 2-3 ikatan. Dari spektrum HSQC diketahui bahwa proton pada ${ }^{1} \mathrm{H}$ 2,90 ppm terikat pada karbon ${ }^{13} \mathrm{C} 88,74$ ppm (C12). Proton pada ${ }^{1} \mathrm{H} 2,10$ ppm terikat pada karbon ${ }^{13} \mathrm{C}$ 34,94 ppm (C-13). Dari spektrum HMBC diketahui bahwa proton pada pergeseran $2,10 \mathrm{ppm}$ bertetangga dengan karbon pada pergeseran kimia 88,74 ppm (C-12), 44,89 ppm (C-14) dan 28,47 ppm (C-15).

Pemeriksaan spektrum massa dengan metoda Electron Impact (EI) menunjukkan bahwa senyawa N-1 memiliki berat molekul yaitu $378(\mathrm{M})+$ dengan rumus molekul C21H30O6. Fragmen dengan m/z 362 mengindikasikan adanya fragmen (M16)+. Fragmen dengan m/z 346 mengindikasikan adanya fragmen (M-32)+. Sedangkan fragmen dengan m/z 313 mengindikasikan adanya fragmen $(\mathrm{M}-65)+$. Sebagai puncak dasar (base peak) yaitu fragmen dengan m/z 313.

Berdasarkan spektrum UV, IR, ${ }^{1} \mathrm{H}$ RMI, ${ }^{19} \mathrm{C}$ RMI, COSY, HSQC, HMBC dan massa diduga struktur senyawa $\mathrm{N}-1$ terdiri dari kerangka inti Quassinoid tipe A (C-21) mengandung dua gugus metoksi serta satu buah gugus OH. Dengan membandingkan data spektrum senyawa N-1 dengan literatur ternyata senyawa $\mathrm{N}-1$ mirip dengan senyawa javanicin A atau javanicin L; 16 keton, rumus molekul $\left(\mathrm{C}_{21} \mathrm{H}_{30} \mathrm{O}_{6}\right)$ dan $\mathrm{BM}=378$ $[10,11]$.

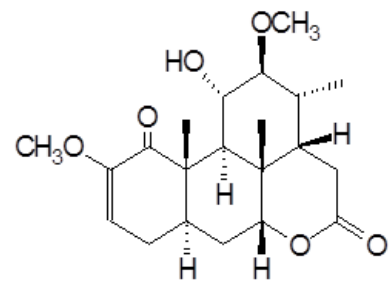

Gambar 1. Struktur kimia javanicin.

\section{KESIMPULAN}

Dari penelitian tentang kajian kimia fraksi etil asetat kulit batang kayu pahit dapat disimpulkan sebagai berikut:

1. Dari $30 \mathrm{~g}$ fraksi etil asetat kulit batang Picrasma javanica. Bldidapatkan senyawa N-I berbentuk kristal jarum, tidak berwarna, rasa pahit, sebanyak $85 \mathrm{mg}$ dengan jarak leleh $179-180^{\circ} \mathrm{C}$.

2. Berdasarkan data spektrum UV-Vis, IR, RMI $\left({ }^{1} \mathrm{H}\right.$ dan $\left.{ }^{13} \mathrm{C}\right) \mathrm{COSY}$, HSQC dan HMBC serta MS disimpulkan senyawa N-I merupakan golongan Quassinoid yaitu Javanicin A atau Javanicin L; 16 keton, rumus molekul $\left(\mathrm{C}_{21} \mathrm{H}_{30} \mathrm{O}_{6}\right)$ dan $\mathrm{BM}=378$.

\section{DAFTAR PUSTAKA}

1. Pedoman pelaksanaan uji klinik obat tradisional. (2000). Departemen Kesehatan Republik Indonesia: Direktorat Jendral POM.

2. Arbain, D., Byrne, L. T., Sargent, M. V., Skelton, B. W., \& White, A. H. (1990). The Alkaloids of Picrasma javanica: Further Studies. Australian Journal of Chemistry, 43(2), 433-437.

3. Arbain, D. (2004). Dua dekade penelitian kimia tumbuhan Sumatera. Bull. Soc. Chem. Nat. Prod. Chem, 4, 1-12.

4. Djamal, R., (1988). Prinsip-prinsip dasar bekerja dalam kimia bahan alam. Padang: Fakultas Matematika dan IImu Pengetahuan Alam Universitas Andalas.

5. Silverstein, R. M., Webster, F. X., Kiemle, D., \& Bryce, D. L. (2014). Spectrometric identification of organic compounds. John Wiley \& Sons.

6. Gritter, R.J., J.M. Bobbit and A.E. Schwarting. (1991). Pengantar Kromatografi (edisi ke-2). diterjemahkan oleh Kosasih Padmawinata. Bandung: Institut Teknologi Bandung.

7. Marston, A., \& Hostettmann, K. (1999). Biological and chemical evaluation of plant extracts and subsequent isolation strategy. In Bioassay Methods in Natural Product Research and Drug Development (pp. 67-80). Springer Netherlands.

8. Houghton, P., \& Raman, A. (2012). Laboratory handbook for the fractionation of natural extracts. Springer Science \& Business Media.

9. Sastrohamidjojo, H. (1991)Spektroskopi. Yogyakarta: Penerbit Liberty.

10. Ohmoto, T., Koike, K., Mitsunaga, K. Fukuda, H., \& Kagei, K. (1989). Studies on the constituents of Indonesian Picrasma javanica. III. Structures of new quassinoids, javanicins A, C and D. Chemical and Pharmaceutical Bulletin, 37(11), 2991-2994.

11. Yosvalina. (1987). Zat Pahit dari Kayu Paik Picrasma javanica. (Skripsi Sarjana Kimia). Padang: Fakultas Matematika dan IImu Pengetahuan Alam Universitas Andalas. 